\title{
A procedure for the introduction of leanness into a company
}

\author{
Davorin Cimermančič ${ }^{1}$ · Janez Kušar ${ }^{2}$ - Tomaž Berlec ${ }^{2}$ (D)
}

Accepted: 30 November 2020 / Published online: 22 January 2021

(c) The Author(s) 2021

\begin{abstract}
Changing a traditional company into a lean one is a very complex and time-consuming process that needs to be addressed in an appropriate way, otherwise the project of introduction of leanness into a company may fail on the one hand and even have a negative impact on business operations of the company on the other. When introducing a change, a step-by-step procedure leading to a progress may be of great help. The paper outlines a general procedure of leanness, an important part of which is a lean agent. A portfolio analysis is also used as a measure of leanness or as an indicator of the desired direction. The applied working methods were mainly active workshops and interviews with employees. The procedure has been tested on an example of a Slovene company; first, the existing situation is outlined, then the leanness steps taken according to the procedure and the final result after the first transition of the procedure.
\end{abstract}

Keywords Lean organisation · Lean production · Lean agent · Change management · Process reorganisation

\section{Introduction and literature review}

The goal of each company is to maximize profits, minimize costs, increase productivity and increase a market share. A company can achieve the set goals in different ways and the goals can usually be packaged in a package called 'Leanness'.

The introduction of leanness has become a trend among the companies again. However, many companies are unaware of the fact that lean production or lean management focuses not only on the production process but also on other nonproductive services. Therefore, some companies have opened departments, whose

Tomaž Berlec

tomaz.berlec@fs.uni-lj.si

1 Tpv d.o.o., Kandijska cesta 60, 8000 Novo mesto, Slovenia

2 Faculty of Mechanical Engineering, University of Ljubljana, Aškerčeva ulica 6, 1000 Ljubljana, Slovenia 
primary task is the introduction of changes, improvements, standardisation of same, and a concern for a constant progress of the company at all levels (Richard et al. 2017).

A company's strategy means a well-planned, thoughtful and proactive action to achieve business goals. Thus, each of the departments or subsystems (Polajnar et al. 2005) in the company can have its own strategy, which must be in line with the company's strategy. The advent of industrial revolutions and globalisation entailed various strategies focusing on the same goal-increase in profits. The most well-known production strategies applied by the companies are:

- Taylor model (polajnar et al. 2005),

- Production model of development (polajnar et al. 2009),

- Market model (polajnar et al. 2009),

- Development \& market model (polajnar et al. 2009),

- Skinner's decision areas (Polajnar et al. 2009),

- Japanese production strategy (Rusjan 2013),

- Industry 4.0 (Zezulka et al. 2016; Mrugalska and Wyrwicka 2017) and

- Industry 5.0 (Ozkeser 2018; Nikolić 2017).

Each of the proposed strategies has its advantages and disadvantages. It has proved that every new strategy is an upgrade of its predecessor. We can say that the latest Japanese production strategy was the beginning of flourishment and progress both in production and service activities. This strategy was first implemented at Toyota. Taiichi Ohno is considered the father of said strategy, who first introduced the principles in the production process of Toyota, the principles that were subsequently included in the Womack, Jones and Ross' famous book Machine that changed the world: The story of lean production (Womack et al. 1990) under the phrase 'Lean production'.

The principles such as JIT (Just in time), Lean production, Total quality management, Six sigma are all aimed at (Russel and Taylor 2006):

- Reduction in losses in a process,

- Quality increase,

- Better efficiency,

- Higher productivity, and

- Better satisfaction of all participants in the process.

Despite their differences, all the principles and methods do not exclude each other since they all share the same purpose, quite on the contrary, their concurrent use is even desirable. Therefore, in one word, all methods can be called Lean management or Lean organisation. When talking about managing or operating the leanness methodologies in a wider sense, besides the company, the entire supply chain is involved, that is from the buyer to the supplier. As shown in the paper (Gjeldum et al. 2017), it is a great advantage if we can simulate influences between suppliers, production and sales. The term lean organisation is a business model for the organisation and management of production, which includes (Russel and Taylor 2006): 
- Product development,

- Process development,

- Production,

- Suppliers, and

- A customer.

The lean production model deals with (Berlec 2016):

- Detection and elimination of unnecessary losses,

- Stock minimisation,

- Reduction in the number of workers,

- Provision of greater material flow,

- Reaching a faster response time, and

- Increasing and reaching $100 \%$ quality,

all with the aim of increasing the added value of the business process effects. When making a transition to lean production it is also necessary to look at the impact on manufacturing flexibility (Lucherini and Rapaccini 2017) and to have a good structured combination of existing resource to gain significant results (Campos et al. 2016).

The lean organisation model is based on three philosophies (Russel and Taylor 2006):

- Jidoka which represents worker's autonomation (the worker is given responsibility for the work well done).

- Kaizen which means continuous improvement and involves system and process improvements. There are two different types of change, radical ones (Kaikaku; call for more planning and are more expensive, this is why they are carried out only sporadically) and permanent ones (Kaizen; essential improvements that are small, simple and inexpensive).

- Just in Time production (JIT) - it is crucial that no stocks are produced in the process, which means that only so much is used as needed.

These three philosophies represent the foundations of all the methods and principles that were later developed to increase the productivity of production processes. One of important methods for identifying process losses and improving the process is the PDCA Cycle (Deming Cycle), which constantly analyses the entire process in order to identify potential improvements. It is based on four crucial steps, Plan-Do-CheckAct, the most important aspect of which lies in the stage of action (Step 4), when it is necessary to restart the entire cycle for subsequent improvements. By doing so, the minimum standards are changed. This is shown in Fig. 1.

Therefore, it is crucial to identify a (new) problem, for which an analysis of the situation (cost-benefit) is performed, on the basis of which a confirmation of the feasibility of the introduced change is obtained. The change is then introduced, standardised, controlled and our work continues (Protzman 2016; Boutros and Purdie 2014). 


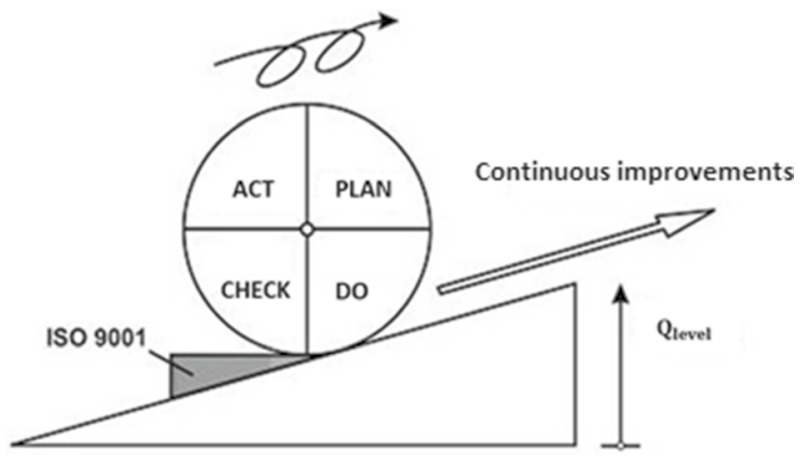

Fig. 1 PDCA cycle of continuous improvements (Soković and Pavletić 2007)

There has been a plethora of attempts to introduce leanness into companies, as the methods per se are very simple at first glance. But when they are actually introduced in a company, it is realised there is much more in the background than just these simple methods. According to Achanga et al. (Achanga et al. 2006), a successful implementation of leanness in a company depends on four factors: management, finance, competence and culture. It is necessary to switch the company's mindset to lean thinking; the support of management is essential as well (Atkinson 2010). The paper (Gaiardelli et al. 2019) highlights how hard and soft lean practices have to interact to enable a successful lean management implementation. A deep understanding of employees and managers about the benefits of their tasks and lean management was introduced in paper (Nguyen 2015). The decision support when introducing leanness in a production system is described in (Herakovič et al. 2014). The paper (Berlec et al. 2018) outlines a methodology used to assist and facilitate a successful implementation of leanness, which, however, does not take into account the lean agent which is one of the key players in a lean organisation.

Therefore, in order to understand the implementation of leanness in the production process, it is also necessary to define the role of a lean agent and his tasks. In practice, a lean agent is also called a change agent. As Lunenberg states (Lunenberg 2012), a change agent is generally any individual or a group of individuals who take on the task of introducing and triggering changes in an organisation. Two types of change agents (internal and external type) are described, which are used according to the different situations encountered by companies. However, after reviewing the literature, we have not come across the role of a change agent dealing with the implementation of lean methods and leanness in the production process and the company. As already mentioned, the person dealing with the leanness area was called a lean agent who acts proactively and is in charge of (Muchira and Kiambati 2015):

- Identifying and presenting a problem,

- Problem solving,

- Connections and communication among the employees,

- Scheduling of activities,

- Fulfilling action plans. 
As to the function which a lean agent can occupy in a company, his work is divided into (Lunenberg 2012; Muchira and Kiambati 2015):

- Counselling, where the agent helps the employees in the company with advice, orients them towards right decisions and problem solving,

- Training, where the agent has the role of a trainer-teacher and transfers knowledge in the form of methods or skills to solve problems to the employees, and

- Research, where the role of the agent is a blend of the previous two roles, the focus being not only on solving current problems but also on preparing a ground for problem solving in the future.

In the context of a lean agent, Ulrich (Ulrich 1996) identifies four distinct roles that he must master:

- Role of a catalyst (initiative and promotion of a change, designer of a team for the implementation of the change, concern for supporting change by a tactical level).

- Role of a sponsor of a change (provides support of the management).

- Role of a facilitator or moderator of the activity relating to the introduction of a change.

- Role of a promotor or demonstrator (demonstration of the introduced change).

Based on the literature review, the described failures and challenges and using simple lean methods, a procedure for introducing leanness into a company will be proposed, which will be based on the involvement of a lean agent.

\section{Methodology}

On the basis of the theoretical starting points and the literature review, a leanness introduction procedure was defined that consists of the following steps:

1. Goal definition

2. Change

3. Current situation inventory

4. Proposals for changes

5. Creativity

6. Decision-making

7. Implementation

8. Control

9. Standardisation

10. Lean mindset

11. $\infty$. Restart 
The validation is made after each step wherein the team checks if the results are consistent with the expectations set out at the beginning of each step; if not, the step is repeated.

The presumptions of this procedure relate to management's willingness and the preparedness of all employees to pursue the goal and support the leanness in the company.

Existing solutions, available budget, slowly changing company culture and knowledge and skills of the employees are seen as limitations.

The leanness introduction procedure is shown in Fig. 2. Its basis is the PDCA cycle or the continuous improvement helix.

The different colours of the steps in Fig. 2 represent the level of difficulty of the respective step:

- Red indicates an alarming state that requires and triggers a change request,

- Orange indicates an intermediate state when the first steps are taken to achieve the goal,

- Yellow indicates a state when the matters are clearly enough identified and ready to be put into practice,

- Violet indicates a neutral state when the team decides as a group and starts working on the implementation of changes in the process,

- Blue indicates the state of implementation and control, which is crucial since at this stage it often turns out what was achieved by the change and what was not,

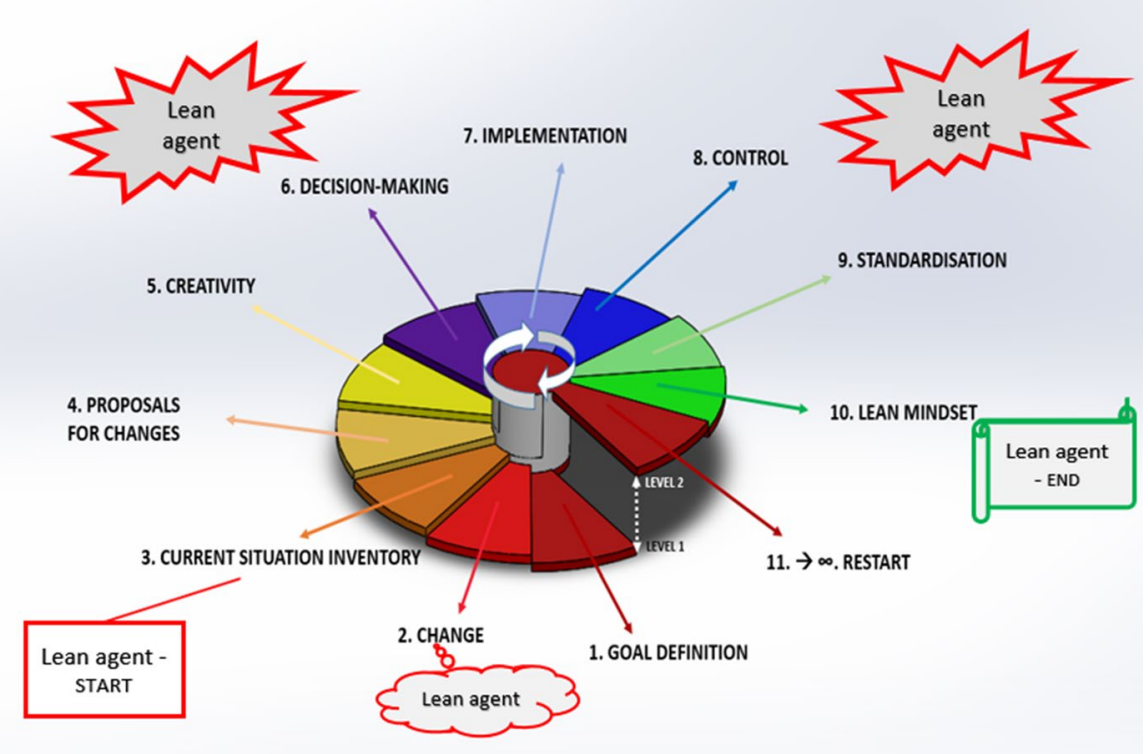

Fig. 2 Illustration of a method diagram serving as a procedure for introducing leanness into a production process 
- Green always indicates the last step in the spiral, which means that the changes were successfully implemented and accepted.

As we can see, the procedure consists of ten steps, each subsequent step being an upgrade of the previous step. So, if we want to move upwards (a positive effect) on the helix, the basis for starting a next step is a well-done previous step, otherwise the helix can rotate downwards and the situation gets worse.

Description of individual steps of the leanness procedure introduction:

\subsection{Goal definition}

The first step is to define the goal and activate a lean agent whose primary task is to control and care for the introduction of changes in the process. The goal is defined as a command from:

- Strategic or tactic level-of the company top management or middle management; most frequently, the goal is simply to increase profits, reduce costs, or increase productivity and efficiency of the company.

- Operative level which usually dictates the improvement of the ergonomics of work and the way how work is performed on production operations.

It is important to set the goals to be feasible since too high, unachievable goals or, on the other hand, too low goals reduce the will to change.

\subsection{Change}

The goal set in the first step triggers the awareness that the goal will not be achievable by the established method of work unless changes are introduced.

By introducing a lean agent in the second step, where he is considered merely as a help in meeting the goals, it is necessary to define his place in the organisational structure of the company (Fig. 3).

In a SME, a lean agent can be an in-house employee (full-time employee), an external employee (as an external consultant in the company) or even an internal external employee (working half-time in the company under consideration). In large companies, only one lean agent will not be enough, so a lean office will need to be organised where more lean agents will be available.

In both of the above cases, however, we need lean teams, for whom the following structure is proposed, according to (Kušar et al. 2008):

Figure 3 shows the organisational structure of a team in charge of introducing leanness into a large company.

The team in charge of introducing leanness consists of lean agents and a sponsor (leadership, owner) who takes care of the support and direction in leanness introduction.

The team in charge of a lean product and process development consists of a lean agent, employees in development and technology and sales. 


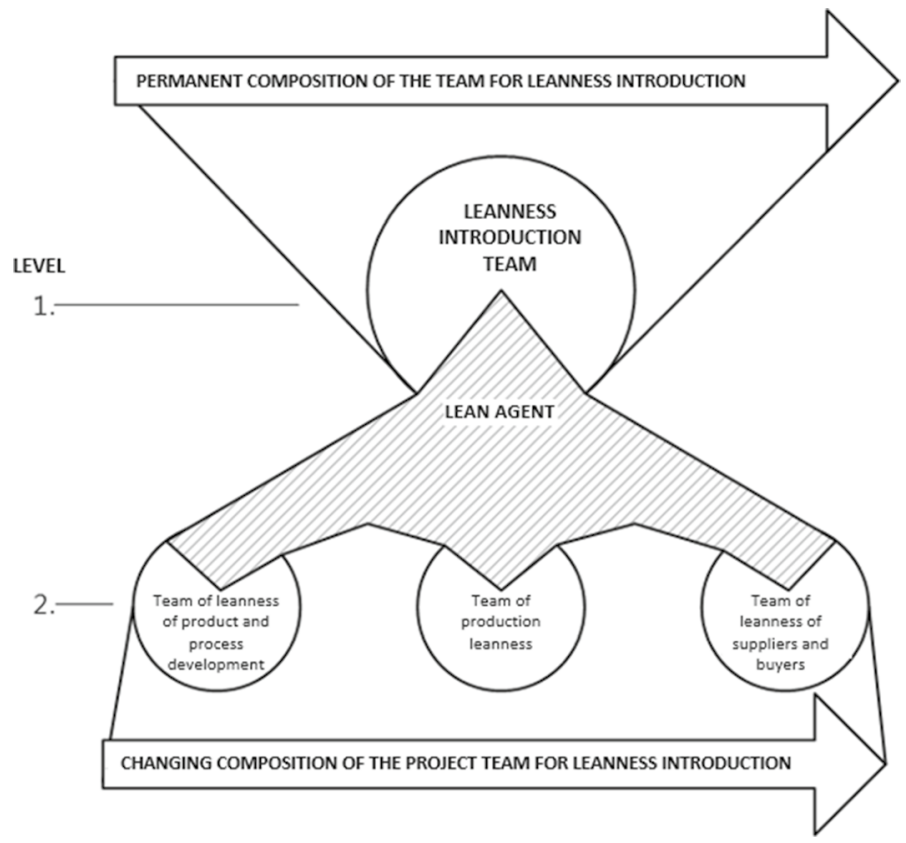

Fig. 3 Organisational structure of a team for the introduction of leanness

The team of lean production consists of a lean agent and employees in production.

The team in charge of the leanness of suppliers and buyers consists of a lean agent, key suppliers and buyers, and employees in acquisition and sales.

In the case of SMEs, the structure of the organisational structure of the team in charge of introducing leanness can be simplified to the extent that no teams are formally formed at the second level, but only informal teams are formed (through interviews with employees, the lean agent gets the necessary information and proposes improvements). The lean agent can manage everything only by the support of the management.

It depends on the company which of the ways to opt for, while the management should consider all advantages and disadvantages. The decision strongly depends on financial input, the qualifications of the internal staff and the time frames for achieving the goal.

\subsection{Current situation inventory}

Step three is the step of making an inventory of the current situation of the process under consideration. This is carried out by qualitative/quantitative methods, such as:

- Various workshops with employees,

- Interviews,

- Documentation review, and 
- Production standardisation with time sampling.

It is desirable to obtain as much information and details as possible since the data cannot be classified as bad and good. When assessing the situation, we make use of the lean production methods, two of them being the most applicable, namely the Value Stream Mapping method, with which a course of information and material streams in a given process is assessed, and the method of identifying wastes in a process ( 8 wastes).

In step three, a lean agent is actively involved in problem solving.

\subsection{Proposals for changes}

On the basis of the obtained data, a lean agent will analyse the current situation of the process and propose changes. When proposing changes, he must be objective and not influenced by external factors. His analysis should clearly indicate:

- Data on the current situation,

- Data obtained by observation,

- Proposed change,

- Anticipated impact of the change on the process, and

- Time frames for the implementation of the change.

\subsection{Creativity}

In this step, the work of a lean agent more concretely involves the employees at the operational level for the first time, since the changes greatly affect their current and future work. A lean agent organises team workshops where, through the methods of creativity, the proposed changes are looked into and an analysis of the rationale and the impact of the changes on the work in the process are performed. The following creativity methods are used (Kušar 2018):

- Brainstorming methods,

- Brainwriting methods,

- Methods of creative orientation,

- Methods of creative confrontation,

- Systematic and analytic methods, and

- method of systematic problem specification.

\subsection{Decision-making}

Depending on the proposals which can be rejected or accepted the following actions are taken:

a. A priority list of introducing proactive activities is prepared, wherein the changes are classified into two types: 
- Small and urgent changes (KAIZEN), wherein little financial input and relatively small efforts are needed, while their impact on the process is visible shortly after the implemented activity.

- Major and radical changes (KAIKAKU), wherein higher financial input is required and the management's approval of the change is requested.

b. A matrix of responsibility (assignment of responsibilities for the implementation of activities) is made.

c. Milestones for monitoring the work progress are defined.

d. An analysis of advantages and disadvantages of the improved situation is performed and the existing situation is compared against the new situation. The analysis presents the calculated savings, profitability and economy of the introduced changes, moreover, simulation tools can be used to calculate different parameters for production planning (MRP, work factor, production planning...).

e. Analysis of the benefits and economic efficiency of the changes.

\subsection{Implementation}

This step is a first encounter with the actual introduction of changes in the process. When manufacturing companies are in question, the primary activity of which is assembly operations and where a human factor is an issue, a gradual introduction of changes and the method of introducing changes are very important factors, since too rapid progress can cause more damage than benefit. To introduce changes, the following lean production tools are most frequently used:

- 5S method for process organisation,

- KANBAN method for process flow,

- FMEA method for process and product analysis,

- SMED method for a quicker exchange of tools.

When introducing changes, an active participation of all employees is required, as this is the only way for the introduced change to achieve the desired objective.

\subsection{Control}

Once the implementation is successfully completed, the new situation should be monitored and, where necessary, all data and activities recorded (what, who, the impact of the change on the process, the response of the employees). It is also necessary to clearly define and develop control procedures to exactly know what needs to be tested and measured in the process. The key task of a lean agent is to educate people and actively participate in the control process. Most often, control is carried out using various methods and tools, such as (Russel and Taylor 2006):

- Key Performance Indicators-KPI

- Total Productive Maintenance-TPM

- Total Quality Management-TQM 
- Overall Equipment Effectiveness-OEE

- 6 sigma,

- Practically (calibres for checking quality, Poka-Yoke...).

Each of these methods provides the data on the success of the process on a daily, weekly, monthly and annual basis. We can also analyse the utilisation of equipment, the process disturbance, the effective and ineffective time of the process. The results are best shown graphically with circular diagrams and presented on tables or on what we call a wall of quality, where the employees can look at the current status of the process and their effectiveness. This creates a greater motivation for the employees to do their job.

\subsection{Standardisation}

In this step, a lean agent is no longer actively involved in the process but only passively. The task of a lean agent is to observe and monitor the proper execution of work and to assist in the event of problems. His role as coordinator, performer and controller in the process is carried out by trained employees.

Of course, a lean agent constantly looks for new improvements in the process.

\subsection{Lean mindset}

The task of a lean agent ends when the changes are fully implemented and completed. It often happens that a lean agent due to his mindset and the use of lean methods stimulates the employees' wishes for a change and innovation, which is the goal of lean manufacturing, encourages awareness of changing the process and assigns responsibilities to individuals for their work. In order to promote a lean mindset, companies decide to collect and discuss innovative proposals from all the employees who contribute to facilitating and speeding up work.

Once the company reaches the desired situation, the task of a lean agent is fulfilled but not completed, as in the continuous improvement cycle there is always something to be improved, and a lean agent is reactivated to implement the steps, following the same procedure, which will bring the company to an even higher level.

\subsection{Restart}

Once step 10 has been completed, step 11 starts. Step 11 is actually a restart (first step), a difference being that step one starts on a higher, leaner level, but only in the event that the introduction of lean measures has been successful. A success can be measured by a leanness portfolio analysis (Jordan et al. 2019) (Fig. 4), where $\mathrm{OEE}$ - overall equipment effectiveness and PE - process efficiency of the production process.

A portfolio analysis is a good indicator of the progress made. The work process then continues in the form of a spiral, which means continuous changes at several levels. Of course, if wrong decisions were made and the implementation 
Fig. 4 Portfolio analysis of leanness (Jordan et al. 2019)

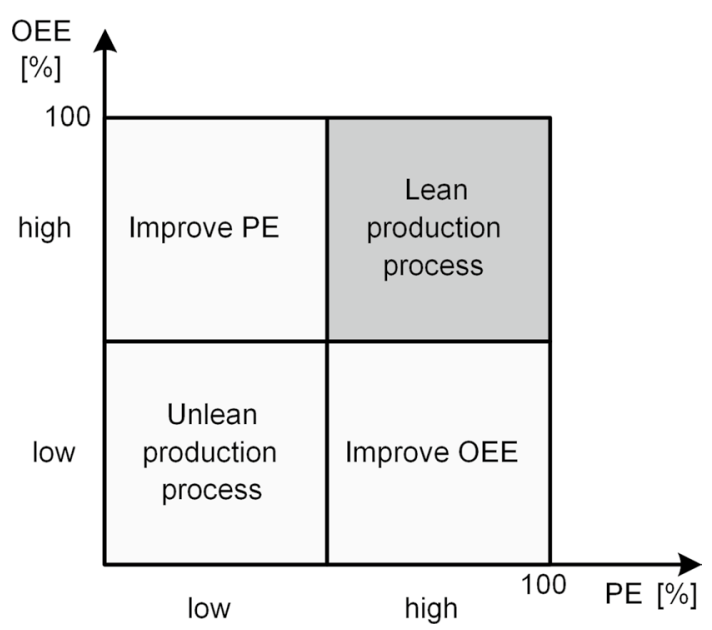

of leanness was poor, we can also climb in the negative direction and can end up on a lower level after the introduction of leanness, that is, with worse results than before the introduction of leanness.

Figure 5 shows a simple Gantt chart of the leanness procedure that shows the duration and time overlap of individual steps.

Figure 5 shows a time course and duration of each step of introduction of leanness using the proposed procedure. As evident, several activities are executed in parallel.

Table 1 shows brief measures for each step separately that the activity carriers must execute before transitioning to a higher level.

The biggest problem encountered in the companies that want a change is that they frequently do not know how and where to start; after initial enthusiasm they fall into a vicious circle, in which they revolve until they have another bright idea. By applying the proposed leanness introduction procedure that guides us through the whole process of introducing leanness and by making use of the portfolio analysis of leanness, we know exactly where we are and where we are moving.

\begin{tabular}{|l|l|l|l|}
\hline 1 & Goal definition & \\
\hline 2 & Change & \\
\hline 3 & Current situation inventory & \\
\hline 4 & Proposal for changes & \\
\hline 5 & Creativity & \\
\hline 6 & Decision-making & \\
\hline 7 & Implementation & \\
\hline 8 & Control & \\
\hline 9 & Standardisation & \\
\hline 10 & Lean mindset & \\
\hline 11 & $\infty$. Restart & \\
\hline
\end{tabular}

Fig. 5 Gantt chart of duration of an individual step 


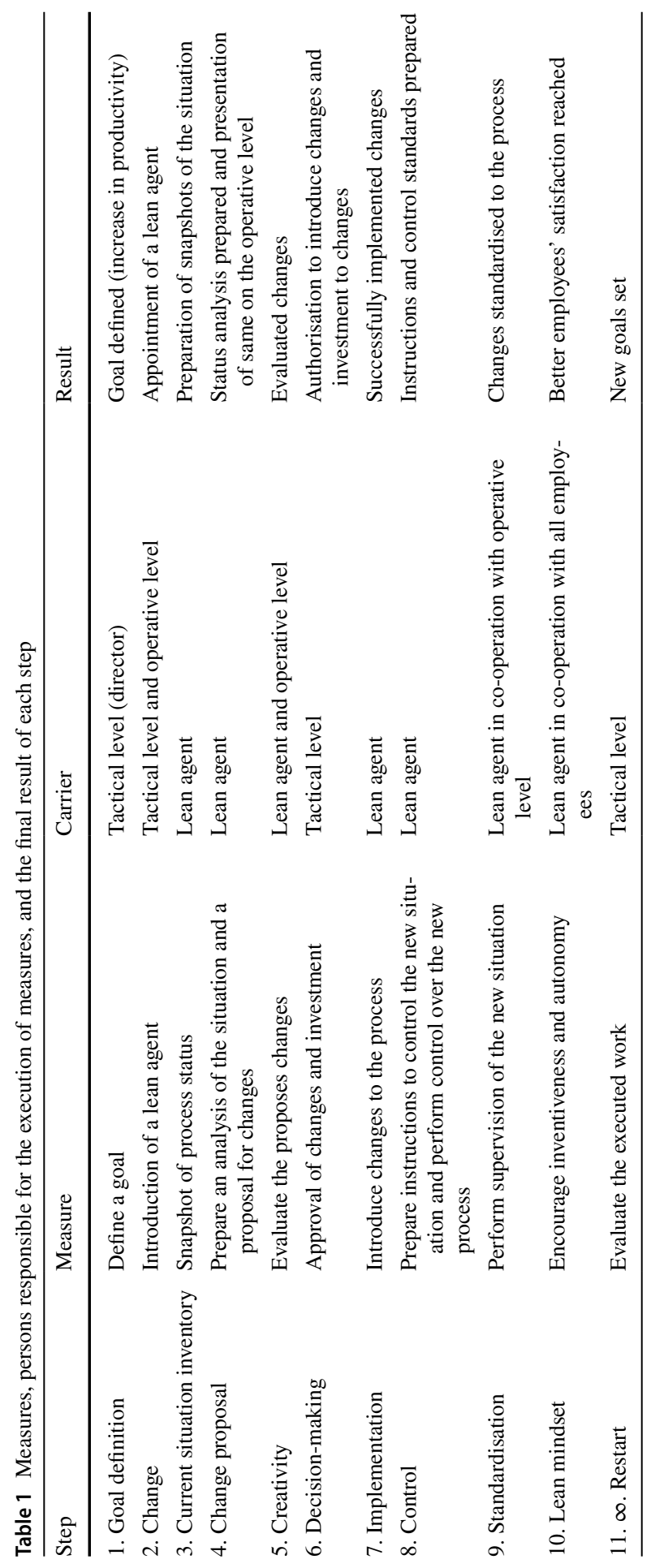




\section{Use of the leanness procedure on an example}

The proposed leanness introduction procedure was tested in a Slovene company. The company is engaged in the production and marketing of mobile homes and modular buildings, floating homes and high-quality glamping tents. The company was founded in 2003 and has produced more than 14,500 units since then. The main product in the product portfolio is mobile homes having different concepts.

For production needs, there are two assembly lines with individual workplaces where manual work is performed. The first assembly line includes the production of mobile homes and the other the production of mobile tents. The company is organized by a matrix structure, in which the main processes are executed in the technical field (production, technology, quality and research \& development). The company has around 250 employees. Since every product is unique, the company is considered to be a trendsetter in the branch.

Our wish was to introduce leanness at all levels and in all departments of the company (acquisition, sales, development, technology, production, quality, logistics). Since the company in question does not have a dedicated department dealing with constant progress, we have appointed a person within the company, who had a good knowledge of leanness and would act as a lean agent.

\subsection{Goal definition}

The goals that have been set both on the tactical level and on the operational level are as follows:

- $10 \%$ increase in productivity,

- $10 \%$ reduction in lead time,

- Ensure $100 \%$ suitability of the material supplied, and

- $50 \%$ reduction in the frequency of errors in the production process,

- Improve work ergonomics.

\subsection{Change}

As the company was small, we decided to simplify the organisational model with non-formal teams on the second level, whose member and at the same time the leader was the lean agent from internal resources, who knew the production processes of the company in detail.

\subsection{Current situation inventory}

With time sampling and standardisation of production, the existing situation of the production process was analysed and an insight into wastes and losses in the process obtained. The sampling was carried out in co-operation with the 
employees, with whom workshops and interviews were later conducted to get a wider picture of the process and obtain more information. Figure 6 shows the results of the first snapshot of the situation.

Figure 6 shows that the production process takes place in line. These are assembly operations whose duration times are shown in the Gantt chart.

\subsection{Proposals for changes}

Depending on the snapshot of the situation and the analysis, a number of key observations were made relating to the entire production process:

- Lack of communication and co-operation between support services (technology, development, acquisition, logistics, production, quality), which is reflected in errors in technical documentation, material launch, product production, lack of instructions for work technology.

- The arrangement of workplaces was below the level demanded by leanness.

- A classic approach of employees to understanding and implementing work procedures.

The proposed changes are entered in Table 3, where an example of a table section with the changes is shown.

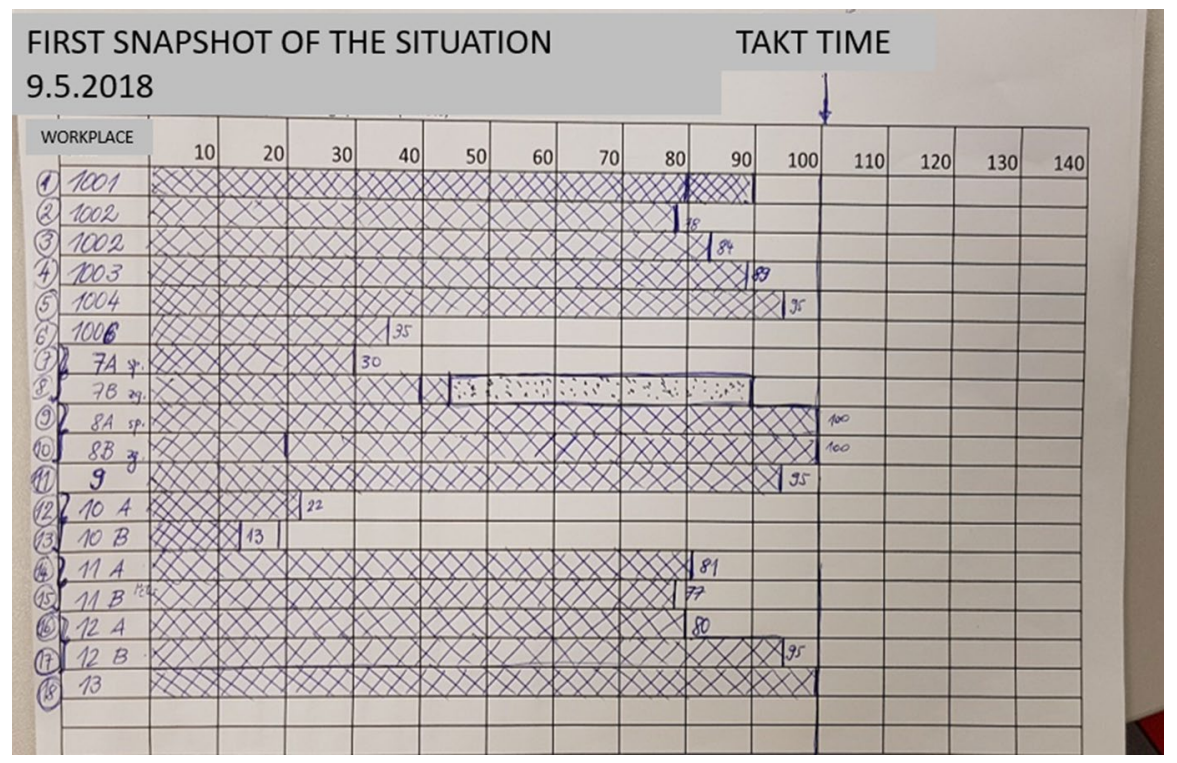

Fig. 6 Presentation of a record and an analysis of the situation of the production process 
Table 2 Comparison of both assembly modes including six persons

\begin{tabular}{llll}
\hline Mode & $\begin{array}{l}\text { Number of compo- } \\
\text { nents per person }\end{array}$ & $\begin{array}{l}\text { Assembly } \\
\text { time (s) }\end{array}$ & $\begin{array}{l}\text { Shortening } \\
\text { of assembly } \\
\text { time }\end{array}$ \\
\hline $\begin{array}{l}\text { Individual work } \\
\text { Team work }\end{array}$ & 12 & 60 & $33 \%$ \\
\hline
\end{tabular}

Table 3 Table section for the analysis and presentation of data with individual tasks

\begin{tabular}{|l|l|l|l|l|l|l|l|l|}
\hline $\begin{array}{l}\text { Cons. } \\
\text { No. }\end{array}$ & $\begin{array}{l}\text { Proposed } \\
\text { change }\end{array}$ & $\begin{array}{l}\text { Description of } \\
\text { the proposed } \\
\text { change and } \\
\text { impact on the } \\
\text { production } \\
\text { process }\end{array}$ & $\begin{array}{l}\text { Workplace } \\
\text { subject to the } \\
\text { introduced } \\
\text { change }\end{array}$ & $\begin{array}{l}\text { Responsible } \\
\text { person }\end{array}$ & $\begin{array}{l}\text { Planned } \\
\text { impleme } \\
\text { ntation } \\
\text { period }\end{array}$ & Savings & $\begin{array}{l}\text { Acceptable/u } \\
\text { nacceptable }\end{array}$ & $\begin{array}{l}\text { Successf } \\
\text { ully } \\
\text { impleme } \\
\text { nted }\end{array}$ \\
\hline 1. & $\begin{array}{l}\text { Installati } \\
\text { on of } \\
\text { protectiv } \\
\text { e film in } \\
\text { the pre- } \\
\text { assembly } \\
\text { phase }\end{array}$ & $\begin{array}{l}\text { Acceleration } \\
\text { of thembly } \\
\text { assecess, } \\
\text { shortening of } \\
\text { the lead time, } \\
\text { better } \\
\text { ergonomics of } \\
\text { work }\end{array}$ & Workplace 2 & Person X & $\begin{array}{l}\text { August } \\
\text { execution }\end{array}$ \\
\hline
\end{tabular}

We can see that a change can be found in three different states, each of which is illustrated by another colour (green-successfully executed, yellow-under execution, red-rejected)

\subsection{Creativity}

We desired to stimulate the employees' desire for and awareness of changes and mutual cooperation in the introduction of changes by organising workshops, in which creativity methods were used. The workshops focused on practical cases where the employees assembled small-size experimental models from several components. The example of one of the workshops was as follows:

- In a first mode, each employee assembled an experimental model by himself, which meant more time needed to assemble the model,

- In a second mode, each employee was assigned one of the assembling operations and the assembling was more rapid, the work was simpler.

The results of the work in both modes are presented in Table 2 .

Table 2 shows that the assembly time in the second mode is faster by $33 \%$, the employees were thus practically demonstrated the effect of lean mindset and team work. 


\subsection{Decision-making}

Table 3 shows a table section for the analysis and presentation of data with tasks and an additional indicator of the status of individual changes. The status of each change was discussed with the employees of the company and as a result a colour status indicator was assigned to each change. The table is a combination of the priority list of the introduction of an activity, the matrix of responsibility, the determination of the milestones and the SWOT analysis.

\subsection{Implementation}

When introducing the changes, we specifically focused on:

- Reduction in the time of production cycle,

- Parallel execution of assembly operations (separation of work to assembly and pre-assembly),

- Active participation of all support services of the company, and

- Employees' satisfaction.

All of this had an impact on shortening the lead time and increasing the leanness of the production process. It can be seen from the snapshot picture (Fig. 5) that:

- The initial cycle time was $100 \mathrm{~min}$, the work was executed by 120 workers.

Since the time of the cycle is the time of the longest operation, which is a bottleneck in the line production process, the main focus was dedicated to eliminating bottlenecks. Often, the bottleneck is only a result of hidden activities and factors that do not have a direct impact on the observed operation. Therefore, it is necessary to look at the process as a whole, as by eliminating the bottlenecks we do not get rid of them, but their number may even increase. In other words, the method of eliminating bottlenecks is also called smoothing of production, which aims to achieve an even distribution of work across all workplaces.

Table 4 lists short measures and tasks that were assigned to each department.

Figure 7 shows the workflow and interdependence in introducing changes into a production process.

Figure 7 shows that any change in the production process affects all departments within the company or the entire supply chain of the company. Therefore, when introducing changes, much attention needs to be paid to communication among employees.

Figures 8 and 9 show a Gantt chart of the workflow at workplaces 2 and 3, in which, in the current situation, all four (assembly) operations are carried out on the line in sequence (OP $1-\mathrm{OP} 2-\mathrm{OP} 3-\mathrm{OP} 4)$, while in a new situation operation 2 is shifted to pre-assembly (it is performed in parallel with operation 1), and a greater number of workers is added to Operation 4 , so that the time needed for the 


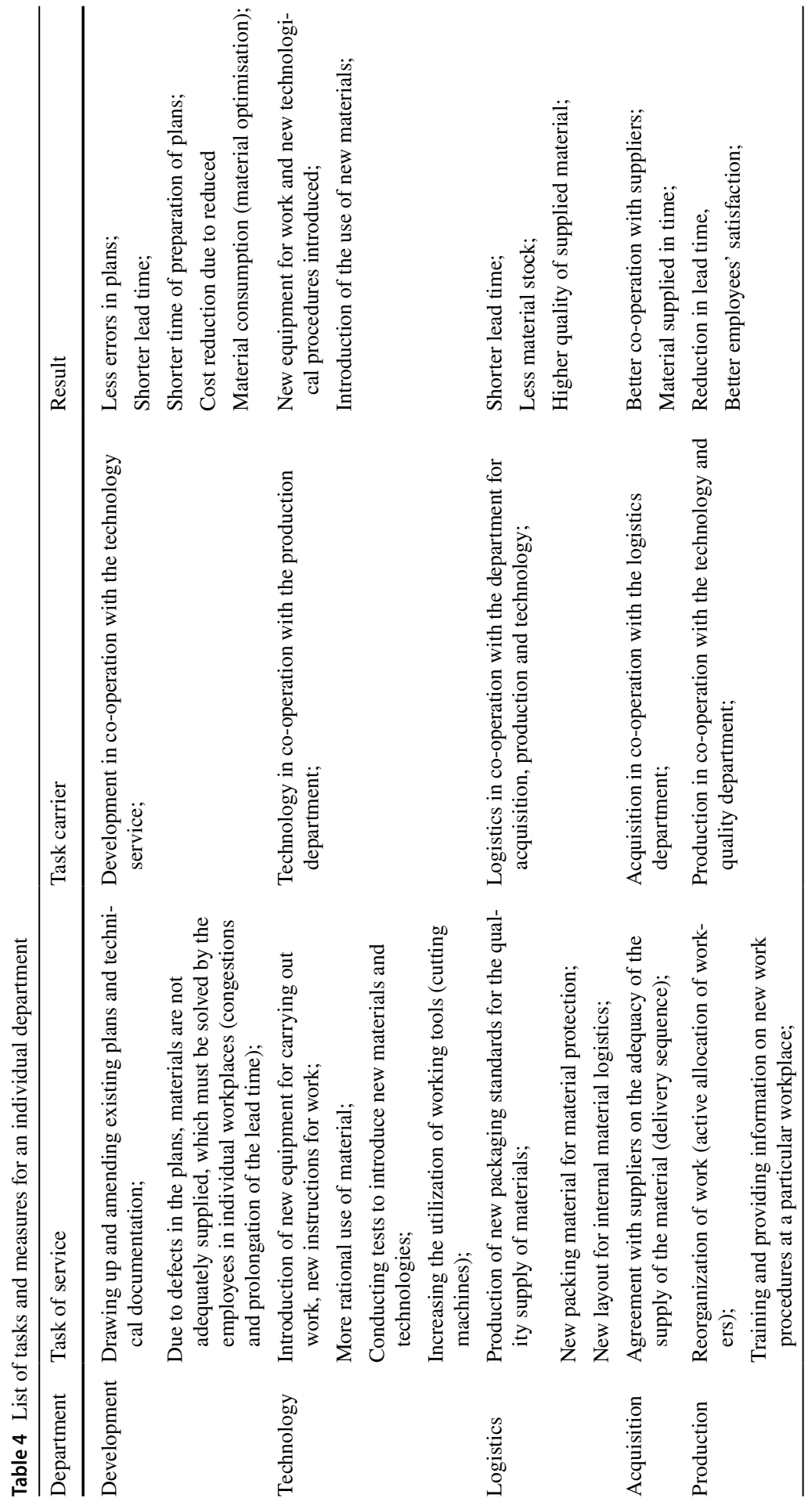




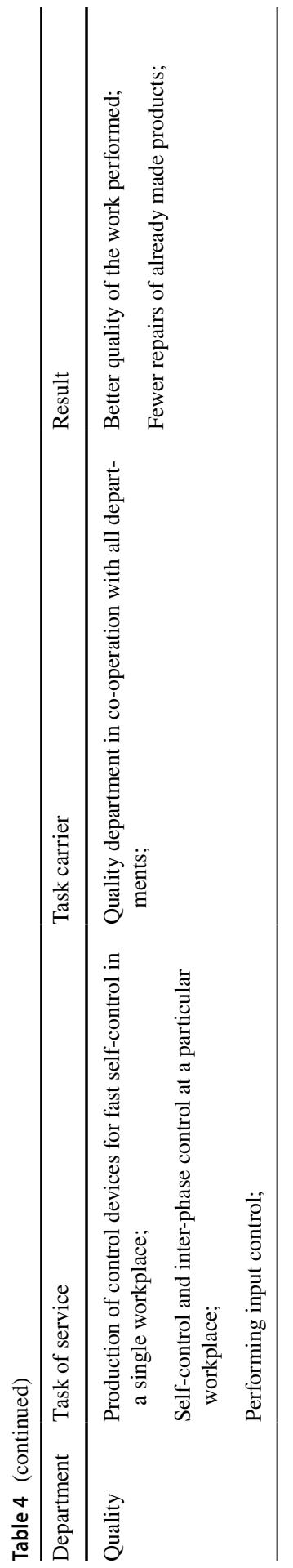




\begin{tabular}{|l|l|l}
\hline 1 & Development & \\
\hline 2 & Technology & \\
\hline 3 & Logistics & \\
\hline 4 & Acquisition & \\
\hline 5 & Production & \\
\hline 6 & Quality & \\
\hline
\end{tabular}

Fig. 7 Gantt chart of interdependence and course of problem solving that is done in a similar order as product development

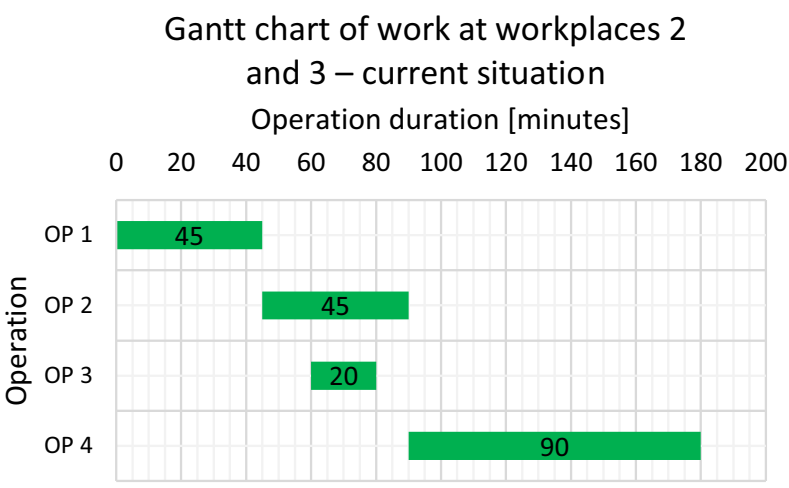

Fig. 8 Gantt chart of a workflow at workplaces 2 and 3 upon the first snapshot of the situation

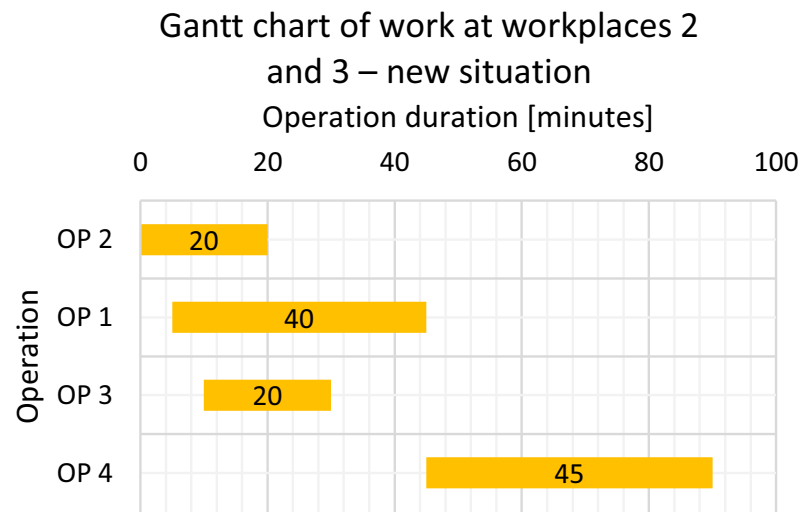

Fig. 9 Gantt chart of a workflow at workplaces 2 and 3 upon the second snapshot of the situation

completion of the work is halved. The principle of work was to define and divide the work to:

- Value added operations, and

- Necessary operations having no added value. 
OP2 is a support operation that does not directly bring any added value but is necessary for the execution of subsequent operations, so it has been moved to the pre-assembly phase.

Table 5 shows a comparison between the current and the improved situation where we focused on the comparison of:

- The necessary area for performing work in both situations,

- A comparison of the cycle time required to perform a job,

- The number of workers required, and

- Ergonomics of employees' work.

We continued with the same work regime in all remaining workplaces, where a significant reduction in the cycle time was also achieved, as well as a reduction in the required number of workers in the process. This raised the efficiency of the process with fewer workers.

\subsection{Control}

In this step, the lean agent made random recordings of the situation and checked the mode and quality of work in accordance with new working procedures, which he had previously defined in co-operation with other support departments, as:

- With the introduction of new equipment into the process,

- With a change in logistics,

- With a change in the layout of the workplace,

- With a change in the packing standards, and

- With employees' deployment

The workflow in all workplaces has changed, which meant changing the criteria and standards (quality) by which the success of a process is measured.

Self-control was introduced, which will become more evident in the next step. Figures 10, 11 and 12 show the control procedures that were produced as a result of a successfully implemented step eight.

Table 5 Comparison of the current and improved situation of the production process at workplaces 2 and 3

\begin{tabular}{lll}
\hline & Current situation & Improved situation \\
\hline Number of job positions & 4 positions & 2 positions \\
Time of average duration of work & $40 \mathrm{~min}$ & $40 \mathrm{~min}$ \\
Time required to complete work at workplaces 2 and 3 & $4 * 40 \mathrm{~min}$ & $2 * 40 \mathrm{~min}$ \\
The number of workers required to complete work & 21 workers & 19 workers \\
Work ergonomics & Poor & Considerably improved \\
\hline
\end{tabular}




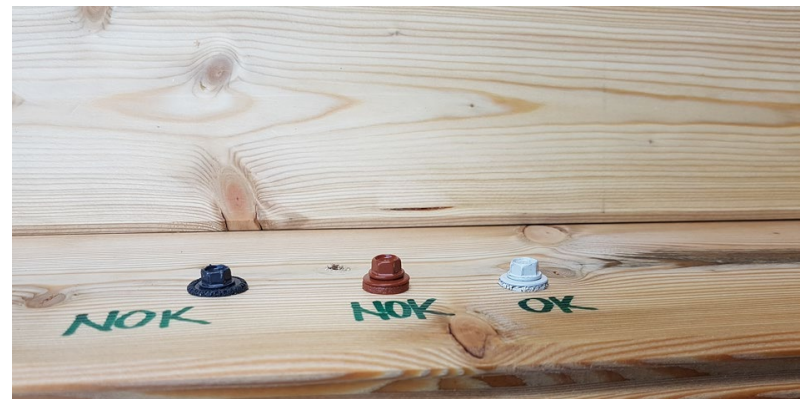

Fig. 10 Image of the screws used in the assembly process. NOK represents a work not well performed, while OK represents an example of an adequately performed assembly

Fig. 11 Performing material control, which is recognised in the process as critical and needs special control and management
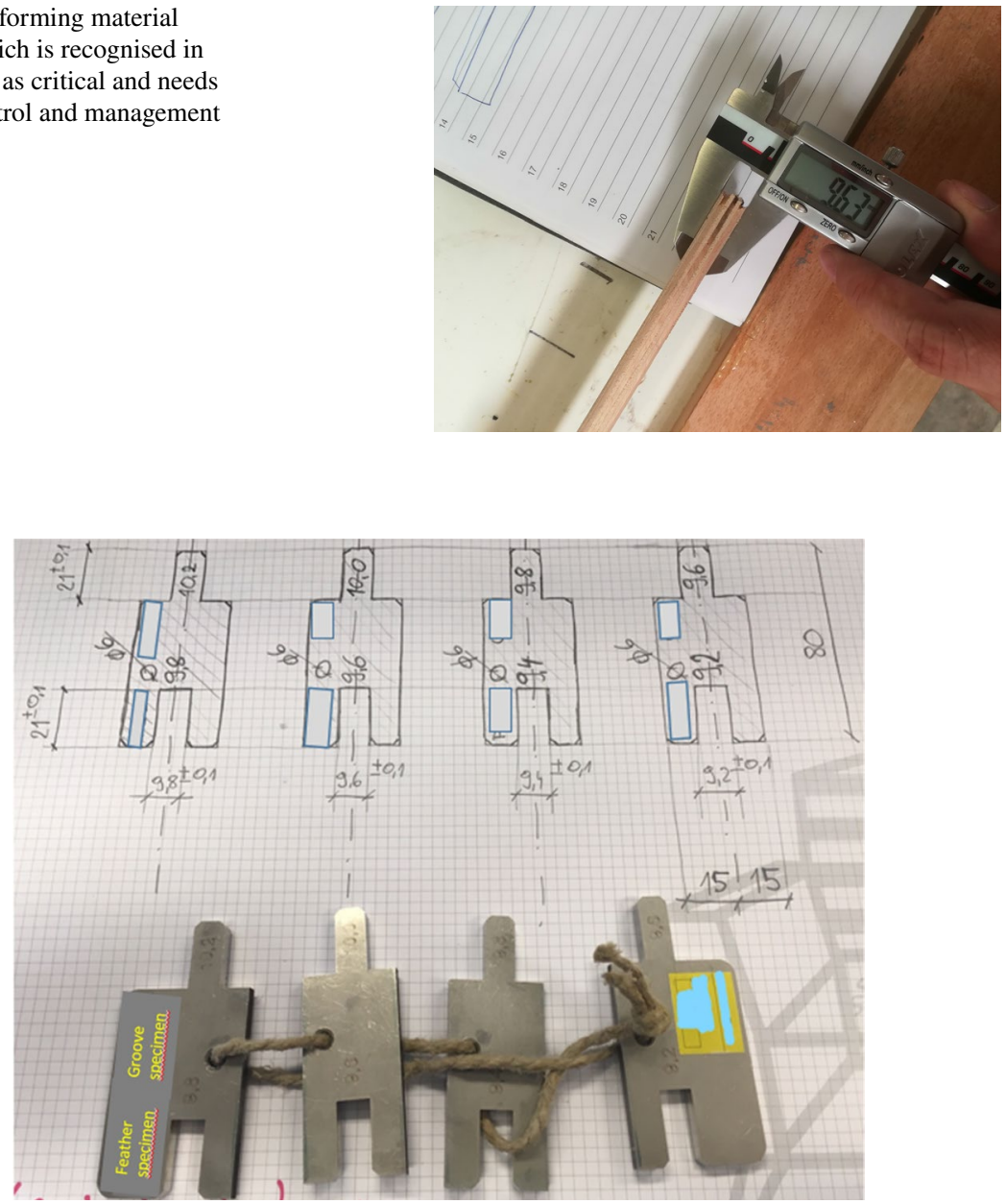

Fig. 12 Illustration of calibres for a rapid performance of input control 
Figure 10 shows an image to assist a person in performing self-control of the work performed.

Figure 11 shows the process of measuring critical material requiring special treatment and quality control.

Figure 12 shows a manufactured calibre used in the input control of the critical material, which reduces the probability of errors later in the process.

\subsection{Standardisation}

The introduction of self-control among the employees brought about the standardisation of the introduced changes, which implied less frequent (passive) involvement of the lean agent in the change introduction process. Therefore, the agent could devote himself to introducing changes and identifying losses in other areas and carried out control only by short rounds of the workplace with the introduced change.

\subsection{Lean mindset}

The last task of the lean agent was to make the employees aware of the leanness, which is also the philosophy of lean production if we want to introduce changes in the process and standardise them. For this purpose, workshops on lean production were organised for the employees, the expectations and goals were presented. By doing so, we directly involved them in the process of continuous improvement and gave them autonomy and responsibility for the work they perform on a daily basis. The company again started collecting internal innovative proposals (IP), which the employees could submit in case they identified and wanted a change in the workflow. The lean agent's task was to:

- Study proposals,

- Analyse,

- Check the purpose of utilisation,

- Prepare a utilisation report (SWOT analysis) for the responsible person, and

- To prepare a response to the person who submitted an IP.

With this measure, we gained greater confidence among our employees as they were once again actively involved in a series of ongoing improvements.

\section{$3.11 \infty$. Restart}

Once the work of the lean agent was completed, the tactical level had to analyse the work done in the past period and set new, measurable and achievable goals on this basis, which the lean agent will tackle in the next iteration of the leanness procedure. In such a sequence, the leanness procedure can be carried out indefinitely, wherein the company can either progress or lag behind. 
Table 6 Presentation of data and a comparison of the current and improved situation based on the data obtained by recording the process

\begin{tabular}{lll}
$\begin{array}{l}\text { First observation (May } \\
2018)\end{array}$ & $\begin{array}{l}\text { Second observation } \\
\text { (October 2018) }\end{array}$ & $\begin{array}{l}\text { Comparison in } \\
\% \text { (improve- } \\
\text { ment) }\end{array}$ \\
\hline $100 \mathrm{~min}$ & $70 \mathrm{~min}$ & $30 \%$ \\
120 & 107 & $10.8 \%$ \\
18 & 16 & $11.1 \%$
\end{tabular}

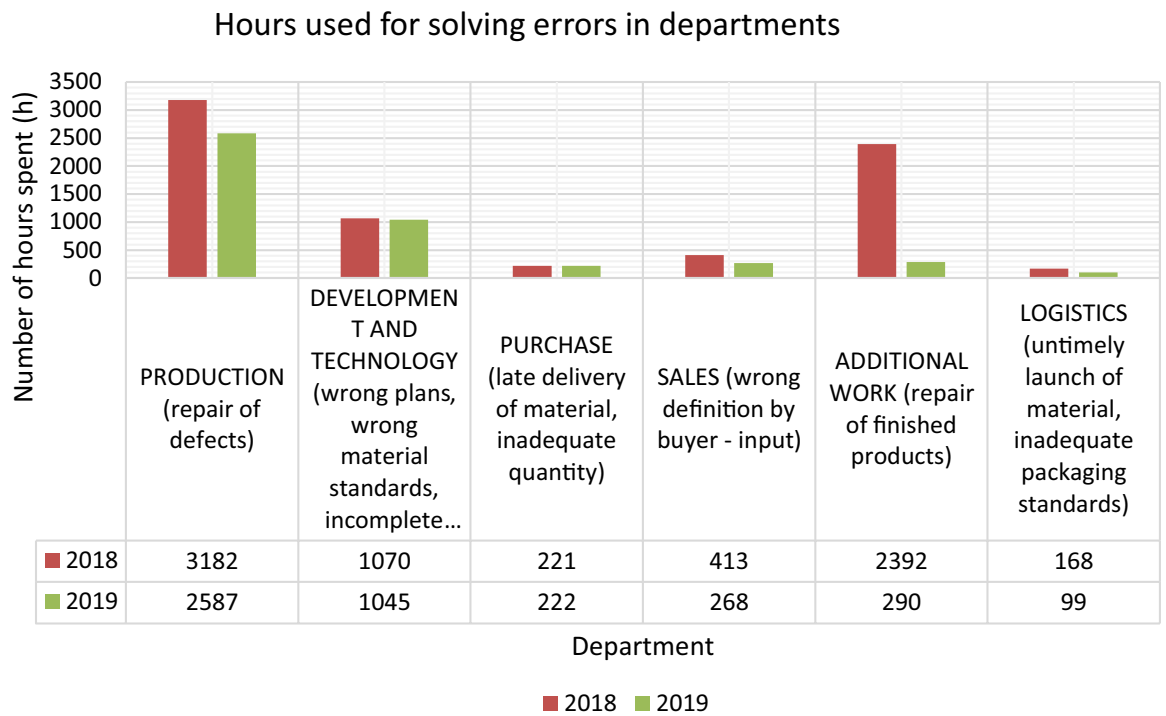

Fig. 13 Hours used for solving errors in departments

\section{Results and discussion}

This chapter will briefly outline the results of our research work.

\subsection{Production process}

To provide a realistic assessment of the work done, it was necessary to wait for some time for the changes to be standardised to the extent that they became mechanisms, about which the workers do not think; this is also one of the leanness philosophies-make it simple. Table 6 shows a comparison between first recording in May 2018 and the second recording in October 2019. 
In the company, effective hours spent on production and downtime are recorded in the MES information system. The hours spent for solving errors in different departments in 2018 and 2019 are shown in Fig. 13.

As shown in Fig. 13, the tendency of hours spent due to congestion is on a decrease, which means that the work of individual departments is improving with the measures introduced. Most errors still occur in production, but the share dropped by $23 \%$ from 2018 to 2019, although the production increased by $10 \%$ and the number of employees was reduced. The improvement is mainly due to auto worker control and inter-phase quality control. However, additional work is still needed because of late material supplies and damages to the product during storage. The effective and total hours used to produce the products in 2018 and 2019 are shown in Fig. 14.

Figure 14 shows that the number of effective and total hours increased from 2018 to 2019 , whereby the effective hours increased by $5 \%$.

To obtain more tangible results, the lead times of production of the same type of product in different production periods (seasons) were compared. Average values of lead times in the 2018 and 2019 season were taken as a sample, where only three different types of products were compared because it was the beginning of the 2018 season, as only three types of products were produced at the time of this paper. The results are shown in Fig. 13.

Figure 15 shows the production lead times for different products named A to $\mathrm{R}$. As indicated, the introduction of leanness in all processes, a decrease in lead times was achieved for all products by at least $3 \%$ on product B and up to $46 \%$ on product $\mathrm{P}$. In general, the biggest difference is noted in high-priced products, the leap is smaller in low-priced products.

Share of hours in the season

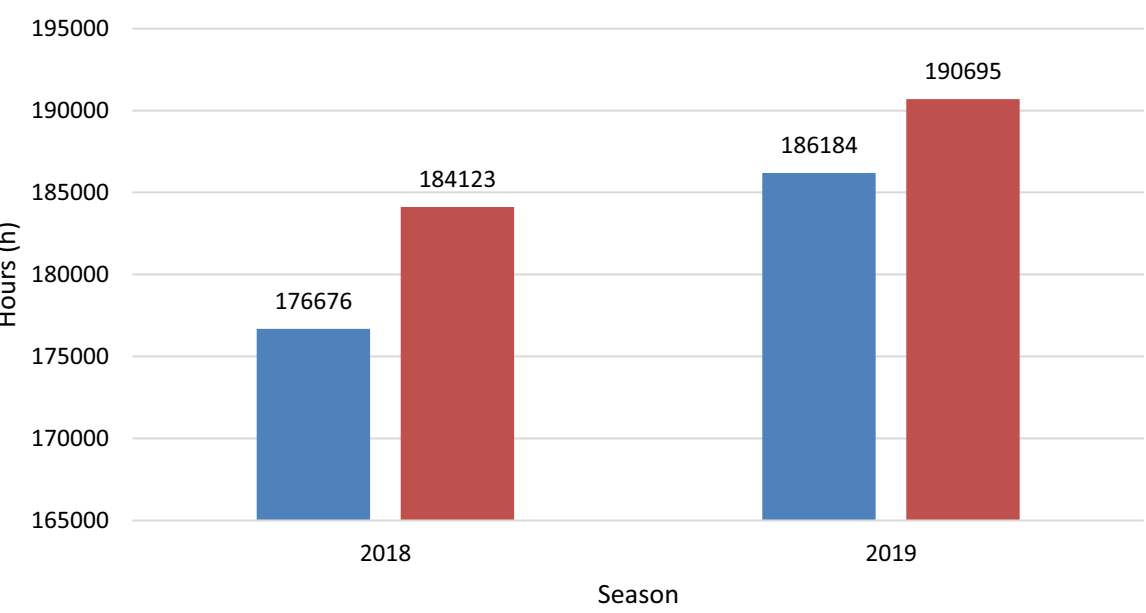

EFFECTIVE HOURS (production hours without downtime) - TOTAL HOURS (effective + downtime)

Fig. 14 Share of hours in the observed seasons 


\section{Production lead time}

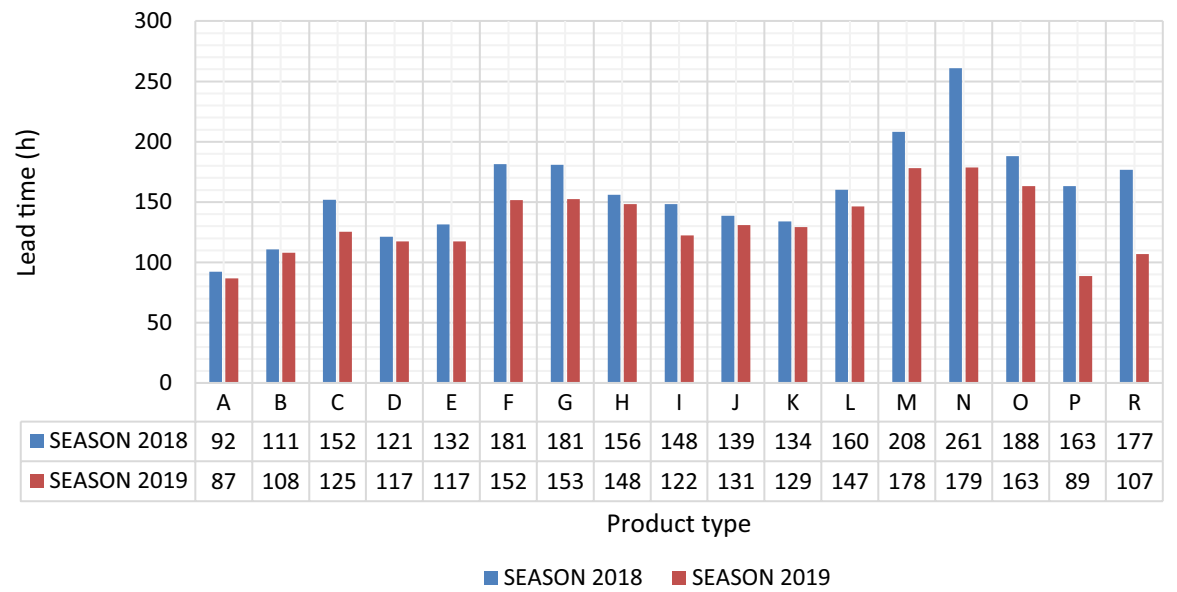

Fig. 15 Presentation and comparison of production lead times from two different periods

The goal of a lean organisation is not only to increase productivity, profit and quality, and reduce stocks, but also increase the efficiency of the work done, and therefore, a simple calculation can also demonstrate the increased efficiency of the process. In general, four efficiency types are distinguished. These are:

- Apparent (increased production with the same number of workers and the same effort, creating stocks in the form of unsold products).

- Proper (production of the same quantity of products as ordered by the buyer with fewer workers and with less effort).

- Overall (efficiency of the entire process).

- Local (efficiency of each individual workplace).

Our calculation has shown that the introduction of a lean agent who was in charge of introducing leanness and a lean organisation into a production process and also into other levels of the company, increased the process efficiency. This was reached by:

- Increase in quality,

- Improvement of employees' satisfaction, and

- Reduction in lead time.

Higher quality was achieved by a regular control of the input material, thereby eliminating the inadequately supplied material from the process prior to launch on the line. As a result, the quality of the material supplied by the suppliers was increased. Since the material was checked twice before being launched to the line (supplier's control and the company's input control), fewer material errors (90\% less errors in the material supplied) were detected on the assembly line and the lead time 
was reduced. The latter was also achieved through auto-control and inter-phase control, as we eliminated the errors in the process immediately (70\% less errors detected on already finished products), which meant less additional work on finished products and higher added value of the product due to reduced pre-processing. By regulating the workplaces, we prevented the unnecessary search of material and equipment at the workplace, and thus also speeded up the assembly time.

Figure 12 shows a portfolio analysis of the existing and improved situations, by which the success of the introduced lean measures is monitored. The blue dot on the graph indicates the existing process, which is located in the first quadrant (PE46\%; OEE-43\%), this means that the PE and the OEE need to be increased, while the red dot indicates the improved situation of the process, in which the lean agent was involved. As we can see from the graph, the improved situation is found in the fourth quadrant (PE-74\%; OEE-65\%), which was the goal of our research; such a process is a lean process. Progress was made in both areas, both in terms of process efficiency (PE) and overall equipment effectiveness (OEE). The values of OEE and PE for each process are also shown in Fig. 16.

\subsection{Sustainable development}

The company devotes a great deal of attention to sorting and care of hazardous substances and waste. Plenty of various types of waste are generated in the production of one production unit, which represents additional liabilities and costs for the company.

In the laboratory, we tested and compared the mechanical properties and resistance of the existing and waste materials to the loads by a tear test. As the existing material, pine wood was used, and alternative materials were various types of wood and PVC materials. Two types of test pieces were prepared (with adhesive and without adhesive, to check the function and yield of the adhesive to the joint strength). The pieces were $500 \mathrm{~mm}$ in length and had screws, the ones as used in the assembly process, fastened $60 \mathrm{~mm}$ apart. Other parameters (depth of

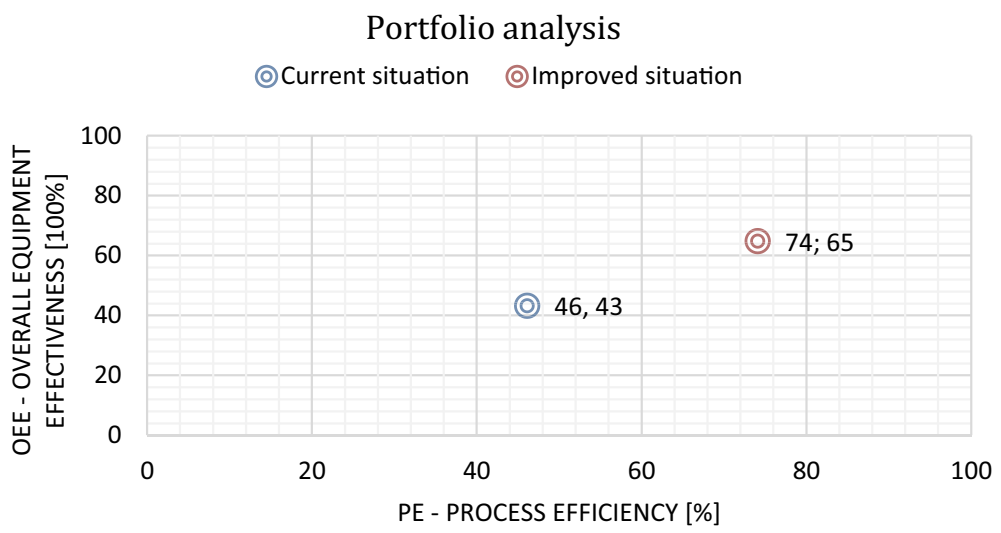

Fig. 16 Portfolio analysis of the existing and new situation 


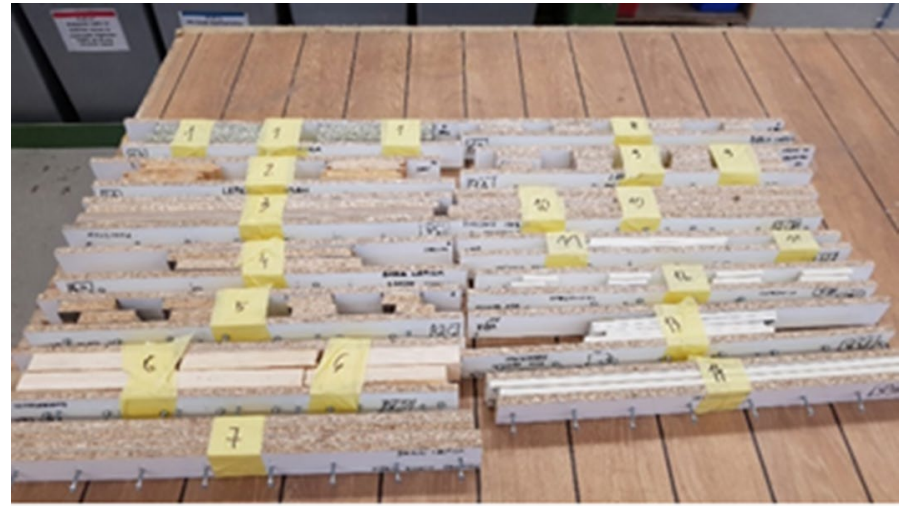

Fig. 17 Presentation of prepared test pieces for the shear test of the screw

screwing) were identical to the conditions in the real process. 6 screws were taken out of each test piece and the values of the force required to take out the screw were averaged due to the measurement uncertainty of the test (different screw depth, distance between the screws). Figure 17 shows the test pieces for the tear test.

The results of the tear test are shown in Fig. 18. We can see that all the test pieces from the waste material meet the minimum requirements of the pulling force of the screw in the tear test.

Based on the data from Fig. 18, it can be concluded that all waste materials (larch waste wood, fibreboard panels, PVC) can be used in a subsequent production process without using adhesive, which means for the company:

\begin{tabular}{|c|c|c|c|c|c|}
\hline & \multicolumn{2}{|c|}{ SAMPLES A - with adhesive } & \multicolumn{2}{|c|}{$\begin{array}{c}\text { SAMPLES B - without } \\
\text { adhesive }\end{array}$} & \\
\hline & $\begin{array}{l}\text { MAX. } \\
\text { FORCE [N] }\end{array}$ & $\begin{array}{l}\text { FORCE at } 10 \% \\
\text { deformation }[\mathrm{N}]\end{array}$ & $\begin{array}{l}\text { MAX. } \\
\text { FORCE [N] }\end{array}$ & $\begin{array}{l}\text { FORCE at } 10 \% \\
\text { deformation [N] }\end{array}$ & \\
\hline MATERIAL 1A & 1008 & 577 & 944 & 533 & MATERIAL 1B \\
\hline MATERIAL 2A & 1231 & 547 & 1319 & 700 & MATERIAL 2B \\
\hline MATERIAL $3 A$ & 965 & 477 & 979 & 603 & MATERIAL 3B \\
\hline MATERIAL 4A & 1184 & 638 & 1096 & 707 & MATERIAL 4B \\
\hline MATERIAL 5A & 1130 & 688 & 1183 & 677 & MATERIAL 5B \\
\hline MATERIAL 6 A & 1171 & 698 & 1228 & 660 & MATERIAL 6B \\
\hline MATERIAL 7A & 1231 & 673 & 1020 & 654 & MATERIAL 7B \\
\hline MATERIAL 8A & 1075 & 592 & 1178 & 670 & MATERIAL 8B \\
\hline MATERIAL 9A & 1109 & 675 & 1255 & 745 & MATERIAL 9B \\
\hline MATERIAL 10A & 1131 & 717 & 1080 & 659 & MATERIAL 10B \\
\hline MATERIAL 11A & 1246 & 771 & 1141 & 857 & MATERIAL 11B \\
\hline \multirow{2}{*}{ MATERIAL 12A } & \multirow{2}{*}{1192} & \multirow{2}{*}{755} & 1273 & 784 & MATERIAL 12B-1 \\
\hline & & & 1204 & 662 & MATERIAL 12B-2 \\
\hline MATERIAL 13A & 766 & 610 & 1227 & 696 & MATERIAL 13B \\
\hline MATERIAL 14A & 1096 & 838 & 113 & 776 & MATERIAL 14B \\
\hline
\end{tabular}

Fig. 18 Table with the results of the tear test 
- Less waste material in the process (the used waste material is used subsequently in the process as an auxiliary material at other workplaces),

- Lower consumption of adhesive,

- Reduced costs (100\%) for the removal of material recycled under special conditions, and

- Increased utilisation of devices with a high level of depreciation (machining centres for cutting), which means reduced costs of a machine hour.

\section{Conclusion}

The paper outlined a universal procedure for the introduction of leanness, consisting of 11 steps, and discussed the role of a lean agent in introducing leanness into the production process. Besides, the leanness portfolio analysis was used to indicate the progress brought about by the measures introduced and define the following step in leanness introduction procedure.

The procedure was tested in a Slovene company. The use of lean production has once again proved to be very useful in improving the operation of a company, since it is applicable to all areas. The key problems that are often demonstrated in practice after the implementation of leanness are standardisation and control of the introduced changes. For control and standardisation purposes, specialised jobs for lean agents are slowly opening up in companies. These agents are responsible for the transfer of information between departments, supervision of work performed and for the process of continuous improvement.

By using the leanness methods, the set goals in the selected company were achieved, namely, increase in the efficiency of the production process, reduction in lead time, cost minimisation and indirectly also increase in the profits; the increase of the OEE and PE parameters resulted in an increased added value. The process effectiveness and the space utilisation were increased by $10 \%$, the lead time was shortened by $30 \%$, the costs of waste material removal were minimised by $100 \%$. This simple procedure demonstrated a simple approach to solving problems and future work of the company, wherein the company should regularly monitor the OEE and PE parameters for monitoring the changes introduced. These two parameters namely determine the level of the leanness of the process. We also laid foundations for the upcoming changes, which are about to come with the advent of digitisation and robotization to the environment. One of the most important steps for the future, which we recommend, is to create a digital twin of the process or to map the production process into a virtual environment, which will mean faster results, analyses and effects of the changes that we want to introduce into the production process, thus achieving a shorter process of introducing changes.

Our research plans in this field are to use this data obtained with the proposed procedure and to use it in the decision model as a base for digital twin simulation, based on which we can find an optimal solution for a next iteration of leanness introduction. 
Open Access This article is licensed under a Creative Commons Attribution 4.0 International License, which permits use, sharing, adaptation, distribution and reproduction in any medium or format, as long as you give appropriate credit to the original author(s) and the source, provide a link to the Creative Commons licence, and indicate if changes were made. The images or other third party material in this article are included in the article's Creative Commons licence, unless indicated otherwise in a credit line to the material. If material is not included in the article's Creative Commons licence and your intended use is not permitted by statutory regulation or exceeds the permitted use, you will need to obtain permission directly from the copyright holder. To view a copy of this licence, visit http://creativecommons.org/licen ses/by/4.0/.

\section{References}

Achanga P, Shehab E, Roy R, Nelder G (2006) Critical success factors for lean implementation within SMEs. J Manuf Technol Manage 17(4):460-471. https://doi.org/10.1108/17410380610662889

Atkinson P (2010) Lean is a cultural issue. Manage Serv 54(2):35-41

Berlec T (2016) Production engineering-templates of lectures. University of Ljubljana, Faculty of Mechanical Engineering, Ljubljana

Berlec T, Kleindienst M, Rabitsch C, Ramsauer C (2018) Methodology to facilitate successful lean implementation. Strojniški vestnik-J Mech Eng 63:457-465

Boutros T, Purdie T (2014) The process improvement handbook: a blueprint for managing change and increasing organizational performance. McGraw-Hill Education, New York

Campos VMK, Cotrim SL, Galdamez EVC, Leal GCL (2016) Introduction of lean manufacturing philosophy by kaizen event: case study on a metalmechanical industry. Indep J Manage Prod 7(1):151-167

Gaiardelli P, Resta B, Dotti S (2019) Exploring the role of human factors in lean management. Int J Lean Six Sigma 10(1):339-366. https://doi.org/10.1108/IJLSS-08-2017-0094

Gjeldum N, Crnjac M, Bilic B (2017) Simulation of bullwhip effect in a supply chain for lean learning factory purposes. Int J Simul Modell 16(4):576-589. https://doi.org/10.2507/IJSIMM16(4)2.390

Herakovič N, Metlikovič P, Debevec M (2014) Motivational lean game to support decision between push and pull production strategy. Int J Simul Modell 13(4):433-446. https://doi.org/10.2507/IJSIM M13(4)4.275

Jordan E, Kušar J, Rihar L, Berlec T (2019) Portfolio analysis of a Lean Six Sigma production process. Cent Euro J Oper Res Springer-Verlag GmbH Germany. https://doi.org/10.1007/s10100-019-00613 $-4$

Kušar J, Bradeško L, Duhovnik J, Starbek M (2008) Project management of product development. Strojniški Vestnik—J Mech Eng 54(9):588-606

Kušar J (2018) Production systems-Templates of Lectures. University of Ljubljana, Faculty of Mechanical Engineering, Ljubljana

Lucherini F, Rapaccini M (2017) Exploring the impact of lean manufacturing on flexibility in SMEs. J Ind Eng Manage-JIEM 10(5):919-945. https://doi.org/10.3926/jiem.2119

Lunenberg FC (2012) Managing change: the role of the change agent. Int J Manag Bus Admin 12(1):1-6

Muchira TN, Kiambati K (2015) The role of human resource development as a change agent. Educ J 4(5):214-221. https://doi.org/10.11648/j.edu.20150405.15

Mrugalska B, Wyrwicka MK (2017) Towards lean production in industry 4.0. Proc Eng 182:466-473

Nguyen DM (2015) A new application model of lean management in small and medium sized enterprises. Int J Simul Modell 14(2):289-298. https://doi.org/10.2507/IJSIMM14(2)9.304

Nikolić G (2017) Is Industry 5.0 responding to Industry 4.0 or its resume. Polytech Des. https://doi. org/10.19279/TVZ.PD.2017-6-2-01

Ozkeser B (2018) Lean Innovation Approach in Industry 5.0. Eurasia Proc Sci Technol Eng Math 2:422-428

Polajnar A, Kalpic B, Leber M (2005) Production management. Faculty of Mechanical Engineering, Maribor

Polajnar A, Kalpic B, Leber M, Kremljak Z, Buchmeister B, Pizmoht P, Vujica Hercog N, Palcic I (2009) Advanced problems in production management. DAAAM International Publishing, Vienna

Protzman C (2016) The lean practitioner's field book: proven, practical, profitable and powerful techniques for making lean really work. CRC Press Taylor \& Francis Group, Boca Raton 
Rusjan B (2013) Management of production and service processes_-second supplemented and, vol modified. Faculty of Economics, Ljubljana

Russel RS, Taylor BW III (2006) Operations management quality and competitiveness in a global environment, 5 edn. Wiley, Hoboken

Richard S, McLean JA, Dahlgaard JJ (2017) Failure of Continuous Improvement initiatives in manufacturing environments: a systematic review of the evidence. Total Qual Manage Bus Excell 28(34):219-237. https://doi.org/10.1080/14783363.2015.1063414

Soković M, Pavletić D (2007) Quality Improvement-PDCA cycle vs. DMAIC DFSS, Strojniški vestnik-J Mech Eng 56(6):369-378

Ulrich D (1996) Human resource champions: the next agenda for adding value and delivering results. Harvard Business School Press, Boston

Womack JP, Jones DT, Roos D (1990) The machine that changed the world: the story of lean production-toyota's secret weapon in the global car wars that is now revolutionizing world industry. Free Press, New York

Zezulka F, Marcon P, Vesely I, Sajdl O (2016) Industry 4.0-An Introduction in the phenomenon. IFACPapersOnLine 49-25:008-012

Publisher's Note Springer Nature remains neutral with regard to jurisdictional claims in published maps and institutional affiliations. 